\title{
Evaluation of Computational Modeling of Electron Transpiration Cooling at High Enthalpies
}

\author{
Kyle M. Hanquist,,- Hicham Alkandry, $\_$and Iain D. Boyd $\stackrel{ \pm}{ \pm}$ \\ University of Michigan, Ann Arbor, Michigan 48109 \\ DOI: $\underline{10.2514 / 1 . T 4932}$
}

\begin{abstract}
A modeling approach for electron transpiration cooling of high-enthalpy flight is evaluated through comparison to a set of experiments performed in a plasma arc tunnel for air and argon. The comparisons include air and argon flow at high enthalpies (27.9 and $11.6 \mathrm{MJ} / \mathrm{kg}$, respectively), with a Mach number of 2.5 to 3 . The conversion of the reported enthalpies and Mach numbers to freestream temperatures and velocities is discussed. The numerical approach is described, including implementation of a thermionic emission boundary condition and an electric field model. Also described is the implementation of a finite-rate chemistry model for argon ionization. Materials with different electron emission properties are also investigated, including graphite and tungsten. The comparisons include two different geometries with different leading-edge radii. The numerical results produce a wide range of emitted current due to the uncertainties in freestream conditions and emissive material properties, but they still agree well with the experimental measurements.
\end{abstract}

\section{Nomenclature}

$A_{R}=$ Richardson constant, $1.20 \times 10^{6} \mathrm{~A} / \mathrm{m}^{2} / \mathrm{K}^{2}$

$C_{p} \quad=$ constant pressure specific heat, $\mathrm{kJ} / \mathrm{kg} / \mathrm{K}$

$D=$ diffusion coefficient, $\mathrm{m}^{2} / \mathrm{s}$

$d \quad=$ distance, $\mathrm{mm}$

$\boldsymbol{E} \quad=$ electric field, $\mathrm{V} / \mathrm{m}$

$g_{j}=$ degeneracy factor of electronic energy level $j$

$h_{t} \quad=$ total enthalpy, $\mathrm{J} / \mathrm{kg}$

$\hbar=$ Planck constant, $6.63 \times 10^{-34}\left(\mathrm{~m}^{2} \cdot \mathrm{kg}\right) / \mathrm{s}$

$J_{\text {ee }}=$ emitted electron current density, $\mathrm{A} / \mathrm{m}^{2}$

$j=$ electric current density, $\mathrm{A} / \mathrm{m}^{2}$

$K_{e}=$ equilibrium constant, $(\mathrm{kg} \cdot \mathrm{mol}) / \mathrm{cm}^{3}$

$k_{B}=$ Boltzmann constant, $1.38 \times 10^{-23} \mathrm{~J} / \mathrm{K}$

$k_{b}=$ backward reaction rate coefficient, $\mathrm{cm}^{6} / \mathrm{kg} / \mathrm{mol}^{2} / \mathrm{s}$

$k_{f}=$ forward reaction rate coefficient, $\mathrm{cm}^{3} / \mathrm{mol} / \mathrm{s}$

$M=$ molar mass, $\mathrm{kg} / \mathrm{mol}$

$M a=$ Mach number

$m=$ mass, $\mathrm{kg}$

$\dot{m} \quad=$ mass blowing rate, $\mathrm{kg} / \mathrm{s} / \mathrm{m}^{2}$

$N_{\mathrm{Av}}=$ Avogadro constant, $6.02 \times 10^{23} \mathrm{~mol}^{-1}$

$n=$ number density, $\mathrm{m}^{-3}$

$p=$ pressure, $\mathrm{Pa}$

$Q_{e}=$ elementary charge, $1.60 \times 10^{-19} \mathrm{C}$

$Q_{\text {int }}=$ internal energy partition function

$q=$ heat transfer, $\mathrm{W} / \mathrm{m}^{2}$

$R_{n} \quad=$ leading-edge radius, $\mathrm{m}$

$R_{u}=$ universal gas constant, $8.31 \mathrm{~J} / \mathrm{K} / \mathrm{mol}$

$s=$ distance along leading edge, $\mathrm{m}$

$T=$ temperature, $\mathrm{K}$

$u=$ velocity, $\mathrm{m} / \mathrm{s}$

$\dot{w}_{e} \quad=$ production rate of electrons, $\mathrm{s}^{-1} \cdot \mathrm{m}^{-2}$

$\dot{w}_{i} \quad=$ recombination rate of ions, $\mathrm{s}^{-1} \cdot \mathrm{m}^{-2}$

Presented as Paper 2015 at the 45th AIAA Thermophysics Conference, Dallas, TX, 22-26 June 2015; received 21 January 2016; revision received 10 June 2016; accepted for publication 12 June 2016; published online 26 August 2016. Copyright (C) 2016 by the American Institute of Aeronautics and Astronautics, Inc. All rights reserved. Copies of this paper may be made for personal and internal use, on condition that the copier pay the per-copy fee to the Copyright Clearance Center (CCC). All requests for copying and permission to reprint should be submitted to CCC at www.copyright.com; employ the ISSN 0887-8722 (print) or 1533-6808 (online) to initiate your request.

*Ph.D. Candidate, Department of Aerospace Engineering. Student Member AIAA.

${ }^{\dagger}$ Research Fellow, Department of Aerospace Engineering. Member AIAA.

¥James E. Knott Professor of Engineering, Department of Aerospace Engineering. Fellow AIAA.

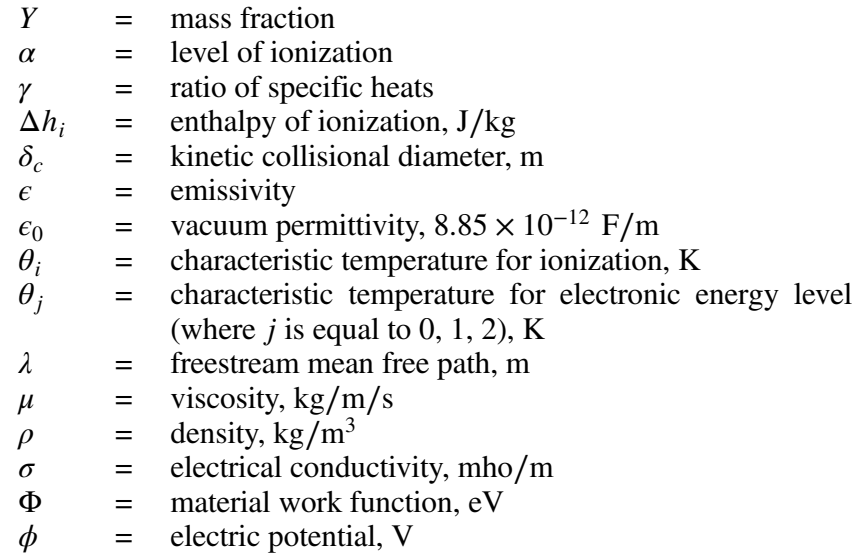

Subscripts

$\begin{array}{ll}\text { Ar } & =\text { argon } \\ a & =\text { axial } \\ \text { ETC } & =\text { electron transpiration cooling } \\ e & =\text { electron } \\ i & =\text { ion } \\ \text { int } & =\text { internal } \\ n & =\text { normal } \\ r & =\text { radial } \\ \text { Sch } & =\text { Schottky } \\ s & =\text { species S } \\ \text { st } & =\text { stagnation } \\ \text { tr } & =\text { translational } \\ \text { vib } & =\text { vibrational } \\ w & =\text { wall } \\ \infty & =\text { freestream }\end{array}$

Superscripts

$\mathrm{Ar}=$ argon

$\mathrm{Ar}^{+}=$argon ion

\section{Introduction}

$\mathbf{H}$ YPERSONIC vehicles, such as the Hypersonic Technology Vehicle 2, require a sharp leading edge in order to increase the lift-to-drag ratio, which increases range. However, the aerodynamic performance gains offered by sharp leading edges come at the cost of intense, localized heating rates. A theoretical analysis first performed by Fay and Riddell [1] revealed that the stagnation point heat transfer 
in hypersonic flow was inversely proportional to the radius of the vehicle leading edge:

$$
q_{w} \propto \sqrt{\frac{\rho_{\infty}}{R_{n}}} u_{\infty}^{3}
$$

One approach to address this issue is to use a leading-edge material that can withstand the high heating rates and temperatures. One type of material that meets this criterion is ultrahigh temperature composites (UHTCs), which were used on the NASA X-43 experimental hypersonic aircraft [2]. Although UHTC materials have good thermal properties, they have some physical limitations such as heavy weight and weak fracture toughness that suggest they are not the ideal approach [3]. Another approach to manage the heat loads is to reject the heat passively, either through heat-shield ablation or radiation. Ablation has significant heat management benefits through essentially a controlled melt of the heat shield while also being lightweight, which makes it a great approach for reentry flight. This shape change of the surface, although permitted for the blunt bodies of reentry flight, is unacceptable for the sharp leading edges of hypersonic vehicles. On the other hand, heat management through radiation does not incur shape change but is limited by the Stefan-Boltzmann law.

An alternative approach that has been recently proposed involves using thermionic materials at the leading edges of hypersonic vehicles [4]. When exposed to high convective heating rates, these materials emit a current of electrons that may lead to a transpiration cooling effect at the surface of the vehicle. This phenomenon is known as thermionic emission and occurs when the thermal energy given to the electrons is greater than the binding potential of the surface material. A recent conceptual study was completed and showed thermionic emission can reduce the surface temperature by approximately $40 \%$ for a Mach 19.4 flow over a sharp leading radius at an altitude of $60 \mathrm{~km}$ with a material work function of $2.0 \mathrm{eV}$ [5]. Given the promising trends in that study, further research is needed to improve the modeling capabilities and to validate the numerical approach. Although using thermoelectric materials as a mechanism to reduce the thermal load on hypersonic vehicles is a recent approach, employing thermionic emission in high-speed flight is not a novel concept. In the 1960 s, there was a push to use thermoelectric materials on the nose of reentry vehicles and collect the emitted electrons as a source of power generation [6,7]. Experiments were performed using the plasma arc tunnel at the Sandia Corporation using a range of different flow conditions, emissive materials, and geometries [8]. This study aims to assess the computational fluid dynamics $(\mathrm{CF} D)$ modeling approach using these experiments.

\section{Numerical Approach}

The numerical simulations in this work are performed using the CFD code LeMANS, which was developed at the University of Michigan [9]. LeMANS is a parallel three-dimensional code that solves the Navier-Stokes equations on unstructured computational grids. LeMANS includes thermochemical nonequilibrium effects, and the flow is modeled assuming that the continuum approximation is valid. It is also assumed that the translational and rotational energy modes can be described by a single temperature $T_{\text {tr }}$ and that the vibrational, electronic, and electron translational energy modes are described by a different temperature $T_{\text {vib }}$. The mixture transport properties are calculated using Wilke's semiempirical mixing rule [10], species thermal conductivities are determined using Eucken's relation [11], and species viscosities are determined using Blottner's curve fits [12].

In LeM $\overline{A N S}$, the set of governing equations is solved using the finite volume method applied to unstructured grids with second-order spatial accuracy. A modified Steger-Warming flux vector splitting scheme [13] is used to discretize the inviscid fluxes across cell faces. The viscous terms are computed using cell-centered and nodal values. The viscous stresses are modeled assuming the flow is a Newtonian fluid and Stokes's hypothesis is applicable, and the heat fluxes are modeled according to Fourier's law for all temperatures. For parallel execution of LeMANS, METIS [14] is used to partition the computational mesh, and a message passing interface is used to communicate the necessary information between processors.

A standard finite-rate chemistry model is used for 11-species reactive air $\left(\mathrm{N}_{2}, \mathrm{O}_{2}, \mathrm{NO}, \mathrm{N}, \mathrm{O}, \mathrm{N}_{2}^{+}, \mathrm{O}_{2}^{+}, \mathrm{NO}^{+}, \mathrm{N}^{+}, \mathrm{O}^{+}\right.$, and $\left.\mathrm{e}^{-}\right)$, and Park's two-temperature model [15] is used to account for the effects of thermal nonequilibrium on the forward and backward reaction rates. A finite-rate chemistry model is also implemented into the numerical method to model the electron-impact ionization reactions for argon. The forward reaction rate coefficient is given by [16]

$$
k_{f}(T)=2.3 \times 10^{34} T^{-3.60} \exp \left(\frac{-182,890}{T}\right)
$$

The backward reaction rate coefficient is then calculated from the equilibrium constant:

$$
K_{e}(T)=\frac{k_{f}(T)}{k_{b}(T)}
$$

The equilibrium constant for the electron-impact ionization reaction of argon is given in [17]. When the chemistry only has an electronimpact ionization reaction, such as with argon, the convergence of the CFD calculation is sensitive to avalanche ionization [15]. This avalanche process, or chain reaction, occurs when the equation becomes active. The high thermal speed of the electrons results in intrinsically high forward rate coefficients, causing the electron density to increase exponentially. This numerical explosion may lead to numerical divergence of the solution. A simple way to negate the probability of numerical explosion is to slowly introduce the electronimpact ionization reaction, which in this study is achieved by linearly ramping up the forward reaction rate constant.

\section{A. Electron Emission}

A boundary condition is implemented into LeMANS to model thermionic emission at the material surface. The production rate of electrons is calculated by

$$
\dot{w}_{e}=\frac{J_{\mathrm{ee}}}{Q_{e} N_{\mathrm{Av}}}-\sum_{i} \dot{w}_{i}
$$

where $J_{\mathrm{ee}}$ is the emission current density, $Q_{e}$ is the elementary charge, $N_{\mathrm{Av}}$ is the Avogadro constant, and $\dot{w}_{i}$ is the recombination rate of ions. The ions at the surface combine with the emitted electrons to form corresponding neutrals. The current density is calculated using Richardson's Law [18]:

$$
J_{\mathrm{ee}}=A_{R} T_{w}^{2} \exp \left(\frac{-\Phi Q_{e}}{k_{B} T_{w}}\right)
$$

where $A_{R}$ is a material constant assumed to be equal to $1.20 \times$ $10^{6} \mathrm{~A} / \mathrm{m}^{2} / \mathrm{K}^{2}$ in the current work, $T_{w}$ is the surface temperature, $k_{B}$ is the Boltzmann constant, and $\Phi$ is the material work function defined as the minimum energy required to remove an electron from the material. In the current work, the work function varies between $4.32 \mathrm{eV}$ (lower bound of tungsten) and $5.0 \mathrm{eV}$ (upper bound of graphite) [19]. It is to be noted that, in the current work, electrons can only be emitted from the surface using Richardson's law [18] and are assumed only to recombine to the surface through recombination with flowfield ions. The recombination rate of ions is calculated assuming that the surface is fully catalytic to ions [20]:

$$
\dot{w}_{i}=\frac{\rho_{i}}{M_{i}} \sqrt{\frac{R_{u} T_{w}}{2 \pi M_{i}}}
$$

where $\rho_{i}$ is the ion density, $M_{i}$ is the ion molar mass, and $R_{u}$ is the universal gas constant. The emitted electrons will carry away energy from the vehicle surface at a flux of [18] 


$$
q_{\mathrm{ETC}}=J_{\mathrm{ee}}\left(\Phi+\frac{2 k_{B} T_{w}}{Q_{e}}\right)
$$

The surface temperature is determined by balancing the heat transfer to the surface (convective and mass diffusion) with the heat transfer away from the surface (radiative and emissive). The gas properties at the surface of the hypersonic vehicle are calculated in LeMANS by solving the species mass balance

$$
\rho_{w} D_{s, w} \nabla Y_{s, w}+\dot{m} Y_{s, w}=M_{s} \dot{w}_{s}
$$

and momentum balance

$$
p_{n}+\rho_{n} u_{n}^{2}=p_{w}+\frac{\dot{m}^{2}}{\rho_{w}}
$$

equations to obtain the species mass fractions $Y_{s, w}$, gas density $\rho_{w}$, and gas normal velocity $u_{n}$. The mass blowing rate $\dot{m}$ is defined as the product of the electron production rate and the electron mass:

$$
\dot{m}=m_{e} \dot{w}_{e}
$$

\section{B. Electric Field}

The electric field can be expressed in terms of an electric potential $\phi$ as

$$
\boldsymbol{E}=-\nabla \phi
$$

where the electric potential is calculated by using Ohm's law and solving the steady-state current continuity equation [21]:

$$
\begin{gathered}
\boldsymbol{j}=\sigma \boldsymbol{E} \\
\nabla \cdot \boldsymbol{j}=\nabla \cdot(\sigma \nabla \phi)=0
\end{gathered}
$$

where $\sigma$ is the electrical conductivity of the plasma. The electrical conductivity in this work is approximated using a semiempirical model developed by Razier [22], which is valid for air and argon:

$$
\sigma=8300 \times \exp \left(\frac{-36,000}{T}\right)
$$

A zero-gradient condition is used at inlet, outlet, and symmetry computational boundaries for the electric potential. At wall

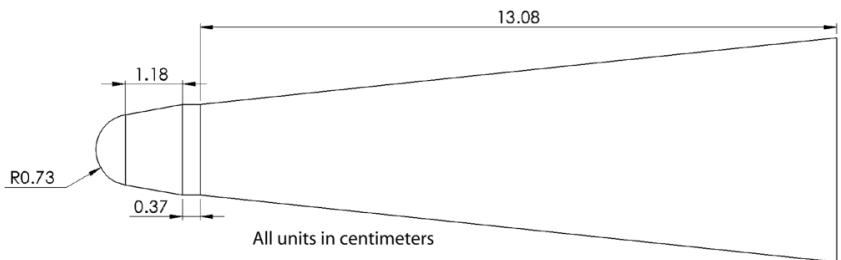

Fig. 1 S-6 geometry.

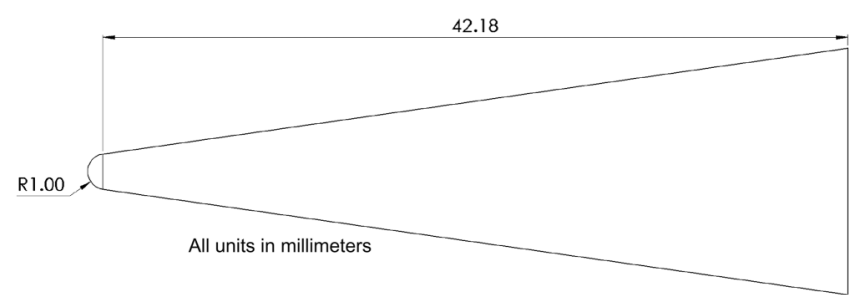

Fig. 2 S-30 geometry. boundaries, the electric potential is calculated by assuming the flowfield ion and electron fluxes are equal at the wall $[21,23]$ :

$$
\phi_{w}=\frac{k_{B} T_{e}}{Q_{e}} \log \left(\frac{n_{i}}{n_{e}} \sqrt{\frac{2 \pi m_{e}\left(T_{i}+T_{e}\right)}{m_{i} T_{e}}}\right)
$$

where $n_{i}$ and $n_{e}$ are the ion and electron number densities, $T_{i}$ and $T_{e}$ are ion and electron temperatures (assumed to be equal to $T_{w}$ in this work), and $m_{i}$ and $m_{e}$ are the ion and electron masses. The effect of thermionic emission is not included in this calculation, which will have an influence on the wall potential.

The electric field at the wall can decrease the energy barrier that the emitted electrons must cross at the surface, which effectively reduces the work function. This is known as the Schottky effect [24]:

$$
\Phi_{\mathrm{Sch}}=\Phi-\sqrt{\frac{Q_{e}^{3} \boldsymbol{E}_{w}}{4 \pi \epsilon_{0}}}
$$

where $\boldsymbol{E}_{w}$ is the electric field at the wall, and $\epsilon_{0}$ is the vacuum permittivity.

\section{Test Case Description}

The experiments of Touryan were performed in Sandia Corporation's plasma arc tunnels in the 1960s [6,8]. A detailed description of the experiments was given in $[\overline{6}, \overline{8}]$. The experiments investigated the effect of different geometries, freestream conditions, and emissive materials on thermionic emission.

\section{A. Geometry}

The experiments used two different geometries, denoted S-6 and S-30. The S-30 geometry has a sharper nose radius and a larger emitter area. The S-6 geometry was an axisymmetric cone with a $0.73 \mathrm{~cm}$ leading nose radius, followed by a 10-deg-angle wedge, a cylinder region, and a 6-deg-angle wedge, as shown in Fig. 1. The geometry was split into two regions: the emitter and collector regions. The emitter region usually consisted of a material with a lower work function than the collector region. The emitter region surface area was $8.4 \mathrm{~cm}^{2}$, consisting of the leading nose radius and the 10-degangle conical body. For this work, the emitter and collector regions were the same material (graphite). The S-30 geometry was an axisymmetric cone with a $1.0 \mathrm{~mm}$ leading nose radius, followed by a 13.5-deg-angle conical body, as shown in Fig. 2. The whole geometry was considered the emitter region and had a surface area of $16 \mathrm{~cm}^{2}$. The material used for this geometry was tungsten.

Meshes were generated for both geometries, and a grid convergence study revealed that the solution was grid independent using these meshes. The computational grid used for the S-6 geometry was axisymmetric and composed of approximately 21,000 cells, with 130 cells in the axial direction and 160 cells in the radial direction. The computational grid used for the S-30 geometry was also axisymmetric and composed of approximately 28,000 cells, with 154 cells in the axial direction and 180 in the radial direction.

\section{B. Emissive Material}

The experiments investigated the effect of using different emissive materials on thermionic emission. The two materials used were graphite and tungsten. The experiments did not cite the material work function or emissivity, so a range of these properties was determined from the literature and is given in Table 1 [19,25-28]. The work functions were significantly higher than those in the previous computational study (2-2.4 eV) [5]. Graphite had a higher emissivity than tungsten, and both varied at the surface temperature range of interest $(2000-5000 \mathrm{~K})$. 
Table 1 Emissive material properties

\begin{tabular}{|c|c|c|c|c|c|c|c|c|}
\hline \multirow{2}{*}{$\frac{\text { Material }}{\text { Graphite }}$} & \multicolumn{3}{|c|}{$\Phi, \mathrm{eV}$} & \multirow{2}{*}{$\begin{array}{l}\text { Reference } \\
{[25,26,19]}\end{array}$} & \multicolumn{3}{|c|}{$\epsilon$} & \multirow{2}{*}{$\frac{\text { Reference }}{[28]}$} \\
\hline & 4.65 & 4.8 & 5.0 & & 0.75 & 0.80 & 0.85 & \\
\hline Tungsten & 4.32 & 4.48 & 4.65 & {$[19,27]$} & 0.30 & 0.35 & 0.40 & [28] \\
\hline
\end{tabular}

Table 2 Freestream properties of Touryan experiments [6]

\begin{tabular}{lccc}
\hline \hline Fluid & $h_{t}, \mathrm{MJ} / \mathrm{kg}$ & Mach number & $p, \mathrm{~Pa}$ \\
\hline Air & 27.9 & $2.5-3$ & 1010 \\
Argon & 11.6 & $2.5-3$ & 1010 \\
\hline \hline
\end{tabular}

\section{Freestream Conditions}

The experiments examined the effect of different enthalpies and working fluids on thermionic emission. The freestream properties cited in the Touryan experiments are given in Table $2[6,8]$.

The numerical method employed requires that the freestream properties are described in terms of temperature, velocity, and density. The following section explains how these properties are determined from Mach number, pressure, and total enthalpy for both air and argon.

\section{Air}

To determine the freestream properties for air, NASA's Chemical Equilibrium with Applications (CEA) computer program is used [29]. This approach accounts for both dissociation and ionization of air. This approach also assumes the freestream flow is in equilibrium, which is not necessarily the case. The converted freestream properties are given in Tables 3 and 4 . The three different Mach numbers are used to cover the range of uncertainty in Mach number, with each Mach number giving different freestream conditions. The freestream mean free path $\lambda$ is calculated by [11]

$$
\lambda=\frac{1}{\sqrt{2} \pi n \delta_{c}^{2}}
$$

where $\delta_{c}$ is the kinetic collisional diameter, which can be approximated by [11]

$$
\delta_{c}^{2} \cong \frac{M_{s}}{9 N_{\mathrm{Av}} \mu} \sqrt{\frac{3 p}{\rho}}
$$

The freestream Knudsen number can be found by dividing the freestream mean free path by the leading-edge radius, which is $7.3 \mathrm{~mm}$ for the S-6 geometry and $1.0 \mathrm{~mm}$ for the S-30 geometry. The largest resulting freestream Knudsen number for the air test cases is

Table 3 Converted freestream properties for air

\begin{tabular}{lcccccc}
\hline \hline$h_{t}$, & Mach & \multicolumn{5}{c}{$u}$, \\
$\mathrm{MJ} / \mathrm{kg}$ & number & $T, \mathrm{~K}$ & $\mathrm{~km} / \mathrm{s}$ & $\rho, \mathrm{kg} / \mathrm{m}^{3}$ & $\mu, \mathrm{kg} / \mathrm{m} / \mathrm{s}$ & $\lambda, \mathrm{m}$ \\
\hline 27.9 & 2.5 & 5330 & 3.99 & $4.41 \times 10^{-4}$ & $1.60 \times 10^{-4}$ & $1.88 \times 10^{-4}$ \\
27.9 & 2.75 & 5260 & 4.31 & $4.58 \times 10^{-4}$ & $1.58 \times 10^{-4}$ & $1.86 \times 10^{-4}$ \\
27.9 & 3 & 5180 & 4.61 & $4.77 \times 10^{-4}$ & $1.56 \times 10^{-4}$ & $1.84 \times 10^{-4}$ \\
\hline \hline
\end{tabular}

0.188. At this Knudsen number, the continuum assumption is less accurate and slip effects can be present, but the effects are expected to be minimal [30].

\section{Argon}

A different approach is used to determine the freestream properties for argon. The CEA computer program currently does not have the capability to account for ionization of argon. Treating argon as an ideal gas, the enthalpy and Mach number can be converted to a temperature and velocity using the following relations:

$$
\begin{gathered}
h_{t}=C_{p, \mathrm{Ar}} T+\frac{(M a)^{2} \gamma R_{u} T}{2 M_{\mathrm{Ar}}} \\
u=M a \sqrt{\frac{\gamma R_{u} T}{M_{\mathrm{Ar}}}} \\
p=\frac{\rho R_{u} T}{M_{\mathrm{Ar}}}
\end{gathered}
$$

where $h_{t}$ is the total enthalpy, $C_{p, \mathrm{Ar}}$ is the constant pressure specific heat of argon, $M a$ is the Mach number, $u$ is the freestream velocity, $\gamma$ is the ratio of specific heats, and $p$ is the freestream pressure. The specific heats for argon are assumed to be constant. The resulting freestream properties without ionization are given in Table 5 . The largest resulting freestream Knudsen number is 0.303 for the Mach $2.5 \mathrm{~S}-30$ test case. At this Knudsen number, the continuum assumption is less accurate and slip effects can be present but the effects are expected to be minimal [30].

The equilibrium level of ionization for argon can be calculated using Saha's equation [11]:

$$
\begin{gathered}
\frac{\alpha^{2}}{1-\alpha^{2}}=\frac{1}{p}\left(\frac{2 \pi m_{e}}{\hbar^{2}}\right)^{3 / 2}\left(k_{B} T\right)^{5 / 2} \frac{2 Q_{\mathrm{int}}^{\mathrm{Ar}+}}{Q_{\mathrm{int}}^{\mathrm{Ar}}} \exp \left(\frac{-\theta_{i}}{T}\right) \\
Q_{\mathrm{int}} \approx g_{0}+g_{1} \exp \left(\frac{-\theta_{1}}{T}\right)+g_{2} \exp \left(\frac{-\theta_{2}}{T}\right)
\end{gathered}
$$

where $Q_{\text {int }}$ is the internal partition function, which is equal to the electronic partition function in the case of argon; $g_{j}$ are the degeneracy factors; $\theta_{j}$ are the characteristic temperatures for electronic excitation of energy level $j$; and $\theta_{i}$ is the ionization energy. Table 6 lists the constants used to calculate the electronic partition function and equilibrium level of ionization [31].

Equation (19) can be modified to account for enthalpy of ioni-

\begin{tabular}{|c|c|c|c|c|c|c|c|c|c|c|}
\hline \multirow[b]{2}{*}{ Mach number } & \multicolumn{10}{|c|}{$Y_{s}$} \\
\hline & $\mathrm{N}_{2}$ & $\mathrm{O}_{2}$ & $\mathrm{~N}$ & $\mathrm{O}$ & NO & $\mathrm{N}_{2}^{+}$ & $\mathrm{O}_{2}^{+}$ & $\mathrm{N}^{+}$ & $\mathrm{O}^{+}$ & $\mathrm{NO}^{+}$ \\
\hline 2.5 & $4.78 \times 10^{-1}$ & $1.25 \times 10^{-5}$ & $2.86 \times 10^{-1}$ & $2.34 \times 10^{-1}$ & $1.38 \times 10^{-3}$ & $1.58 \times 10^{-6}$ & $2.75 \times 10^{-8}$ & $7.51 \times 10^{-6}$ & $9.30 \times 10^{-6}$ & $2.88 \times 10^{-4}$ \\
\hline 2.75 & $5.13 \times 10^{-1}$ & $1.50 \times 10^{-5}$ & $2.52 \times 10^{-1}$ & $2.34 \times 10^{-1}$ & $1.53 \times 10^{-3}$ & $1.14 \times 10^{-6}$ & $2.49 \times 10^{-8}$ & $4.61 \times 10^{-6}$ & $6.67 \times 10^{-6}$ & $2.60 \times 10^{-4}$ \\
\hline 3 & $5.48 \times 10^{-1}$ & $1.84 \times 10^{-5}$ & $2.16 \times 10^{-1}$ & $2.34 \times 10^{-1}$ & $1.70 \times 10^{-3}$ & $7.71 \times 10^{-7}$ & $2.21 \times 10^{-8}$ & $2.62 \times 10^{-6}$ & $4.57 \times 10^{-6}$ & $2.30 \times 10^{-4}$ \\
\hline
\end{tabular}
zation, assuming that the specific heat of argon ions and neutrals are equal [32]:

Table 5 Converted freestream properties for argon without ionization

\begin{tabular}{lcccccc}
\hline \hline$h_{t}$, & Mach & \multicolumn{4}{c}{$u}$, \\
$\mathrm{MJ} / \mathrm{kg}$ & number & $T, \mathrm{~K}$ & $\mathrm{~km} / \mathrm{s}$ & $\rho, \mathrm{kg} / \mathrm{m}^{3}$ & $\mu, \mathrm{kg} / \mathrm{m} / \mathrm{s}$ & $\lambda, \mathrm{m}$ \\
\hline 11.6 & 2.5 & 7250 & 3.96 & $6.69 \times 10^{-4}$ & $2.13 \times 10^{-4}$ & $3.03 \times 10^{-4}$ \\
11.6 & 2.75 & 6350 & 4.08 & $7.64 \times 10^{-4}$ & $1.94 \times 10^{-4}$ & $2.60 \times 10^{-4}$ \\
11.6 & 3 & 5590 & 4.18 & $8.68 \times 10^{-4}$ & $1.78 \times 10^{-4}$ & $2.23 \times 10^{-4}$ \\
\hline \hline
\end{tabular}

Table 4 Air mass fractions of freestream 
Table 6 Constants used to calculate equilibrium level of ionization for argon

\begin{tabular}{lcc}
\hline \hline & $\mathrm{Ar}$ & $\mathrm{Ar}^{+}$ \\
\hline$\theta_{i}, \mathrm{~K}$ & 183,000 & -- \\
$\theta_{1}, \mathrm{~K}$ & 134,061 & 2,061 \\
$\theta_{2}, \mathrm{~K}$ & 134,934 & 156,478 \\
$g_{0}$ & 1 & 4 \\
$g_{1}$ & 5 & 2 \\
$g_{2}$ & 3 & 2 \\
\hline \hline
\end{tabular}

Table 7 Converted freestream properties for argon with ionization

\begin{tabular}{lccccc}
\hline \hline$h_{t}, \mathrm{MJ} / \mathrm{kg}$ & Mach number & $T, \mathrm{~K}$ & $u, \mathrm{~km} / \mathrm{s}$ & $\rho, \mathrm{kg} / \mathrm{m}^{3}$ & $\alpha$ \\
\hline 11.6 & 2.5 & 7170 & 3.94 & $6.80 \times 10^{-4}$ & $3.59 \times 10^{-3}$ \\
11.6 & 2.75 & 6340 & 4.08 & $7.68 \times 10^{-4}$ & $5.78 \times 10^{-4}$ \\
11.6 & 3 & 5590 & 4.18 & $8.71 \times 10^{-4}$ & $7.08 \times 10^{-5}$ \\
\hline \hline
\end{tabular}

$$
h_{t}=C_{p, \mathrm{Ar}} T+\frac{(M a)^{2} \gamma R_{u} T}{2 M_{\mathrm{Ar}}}+\alpha \Delta h_{i}
$$

where $\Delta h_{i}$ is the enthalpy of ionization for argon.

The resulting freestream properties accounting for ionization are given in Table 7. Accounting for ionization results in slightly lower freestream temperatures and velocities, especially for the Mach 2.5 case. This approach also assumes that the flow is in equilibrium, which is not necessarily the case. Although the level of ionization is low, it is still useful to include charged particles in the freestream for stability of the numerical method and for the recombination of the ions to the assumed fully catalytic, material surface.

\section{Numerical Results}

The goal of this study is to compare current thermionic electron emission modeling approaches to previous experiments using a range of different freestream conditions, emissive materials, and geometries.

The flowfield features for the conditions investigated in this study are shown in Fig. 3. Figure 3 presents the temperature contours for the Mach 2.75 cases for air and argon for each geometry without emission. For the air cases, the fluid temperature rises to above
$12,000 \mathrm{~K}$ for the S-6 geometry and to nearly $11,000 \mathrm{~K}$ for the S-30 geometry across the bow shock, before decreasing in the shock layer. The S-6 geometry bow-shock temperature is higher (as expected) due to the more blunt leading edge. The fluid temperature is much hotter for argon, reaching $21,000 \mathrm{~K}$ for the S-6 geometry and nearly $19,000 \mathrm{~K}$ for the S-30 geometry across the bow shock, before decreasing in the shock layer. This is also expected due to the much higher freestream temperature of argon. The air cases also can dissipate energy through dissociation, which lowers the temperature. Figures $\underline{4}$ and $\underline{5}$ present the temperature contours for the Mach 2.75 air and argon cases for each geometry with and without emission. The top half corresponds to the results obtained without emission, and the bottom half is for the results obtained with thermionic emission. The case without emission is analogous to using a thermoelectric material with an infinite work function or a work function that is much greater than the surface temperature. The material for the S-6 geometry is graphite, and the material for the S-30 geometry is tungsten. Figures $\underline{4}$ and $\underline{5}$ show that thermionic emission has an overall minimal effect on the flowfield features for the S-6 cases. However, for the S-30 cases, Figs. 4 and 5 show that thermionic emission changes the shock structure slightly. This is due to the surface temperature decreasing greatly with emission for the S-30 cases.

Figure 6 presents the distribution of translational and vibrational temperatures along the stagnation line for the Mach 2.75 air cases with and without emission. The work function is $4.8 \mathrm{eV}$ for the S-6 case and $4.48 \mathrm{eV}$ for the S-30 case. The emissivity is 0.8 for the S- 6 case and 0.35 for the S-30 case. Figure 6 shows that thermionic emission has an overall minimal effect on the stagnation line temperatures for the S-6 case and that the flow is in thermal nonequilibrium for both cases. For the S-30 case, emission slightly adjusts both the translational and vibrational temperatures. This is due to the wall temperature being much lower for the case with emission. Figure 7 presents the charged species number-density profiles along the stagnation line for the Mach 2.75 air cases with and without emission. As can be expected, thermionic emission increases the electron number density at the surface. The ion number density decreases closer to the leading edge for the case with thermionic emission due to recombination with electrons. Figure 8 presents the charged species number-density profiles along the stagnation line for the Mach 2.75 argon cases with and without emission. Thermionic emission once again increases the electron number density at the surface and decreases the ion number density at the leading edge due to recombination with electrons. Figures 7 and 8 also show that the flow is neutrally charged except near the wall.

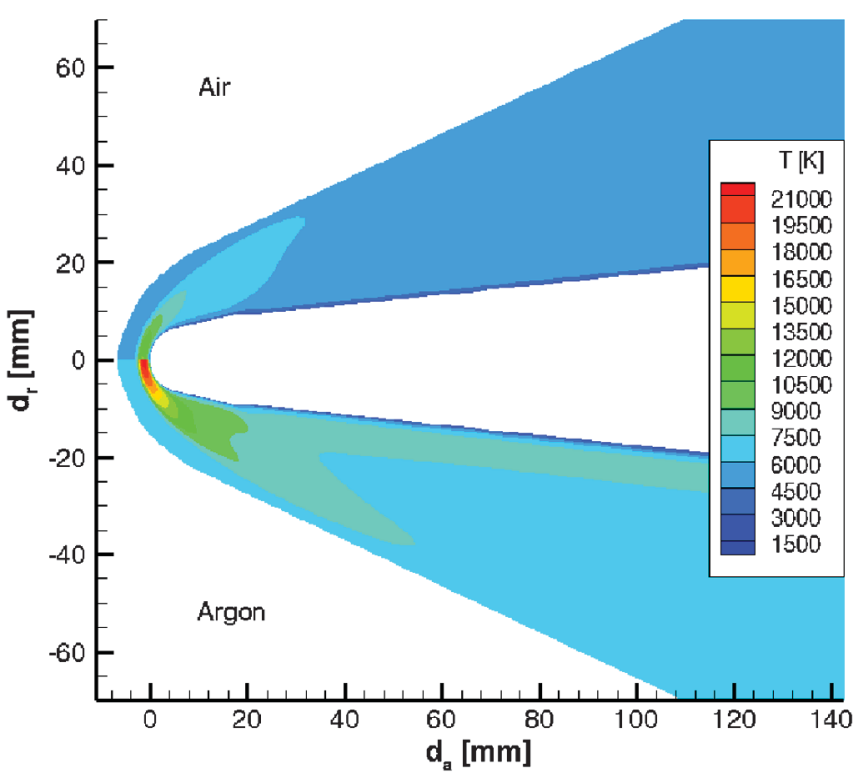

a) $\mathrm{S}-6(\epsilon=0.80)$

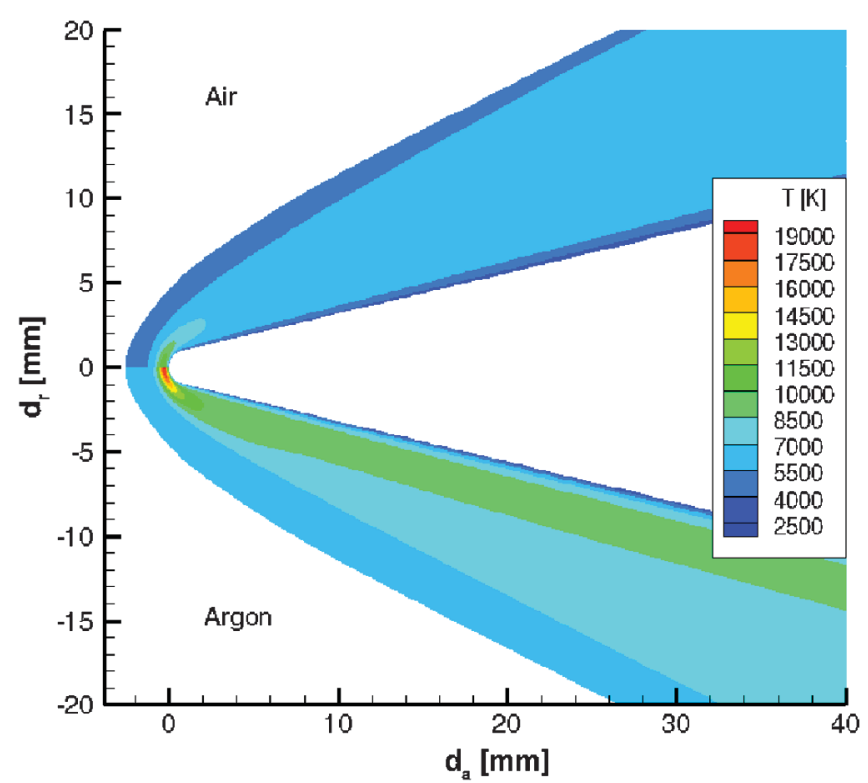

b) $\mathrm{S}-30(\epsilon=\mathbf{0 . 3 5})$

Fig. 3 Temperature contours for Mach 2.75 cases without emission: air (top) and argon (bottom). 


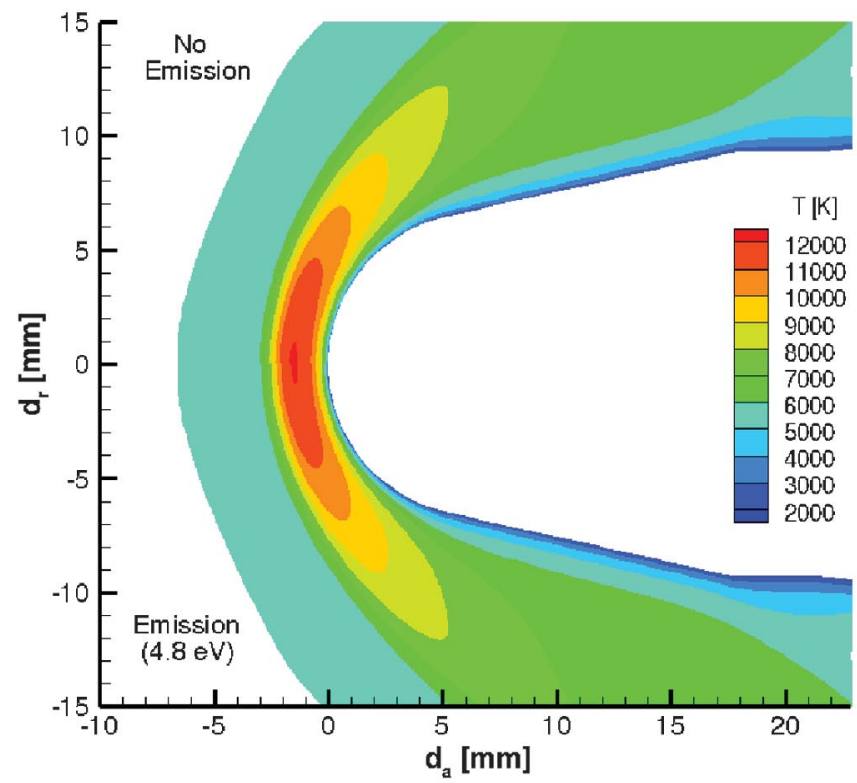

a) $\mathrm{S}-6(\epsilon=0.80)$

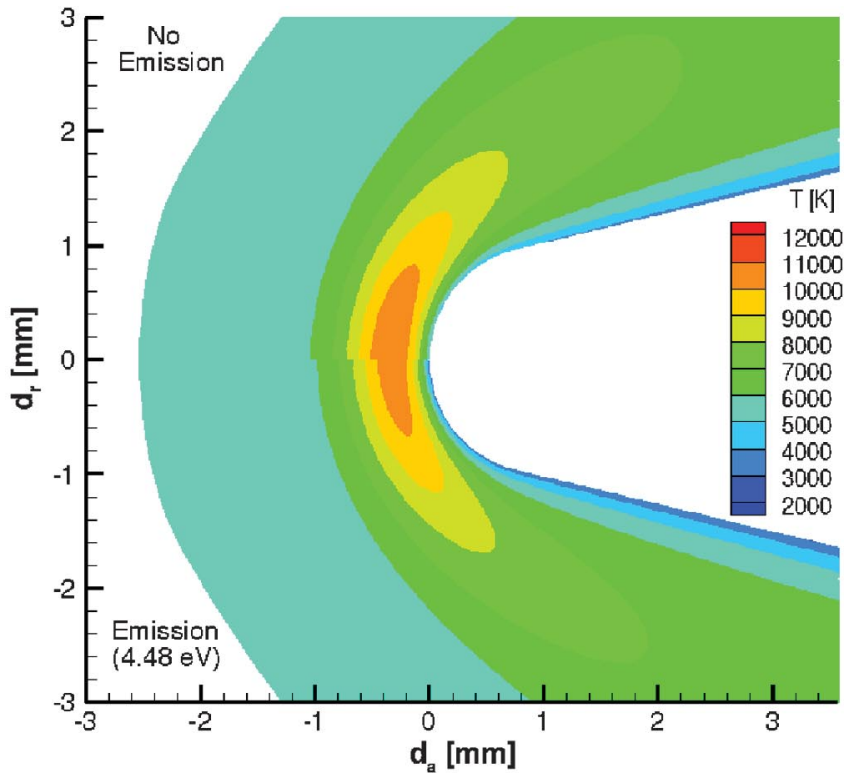

b) $\mathrm{S}-30(\epsilon=\mathbf{0 . 3 5})$

Fig. 4 Temperature contours for Mach 2.75 air: without emission (top) and with emission (bottom).

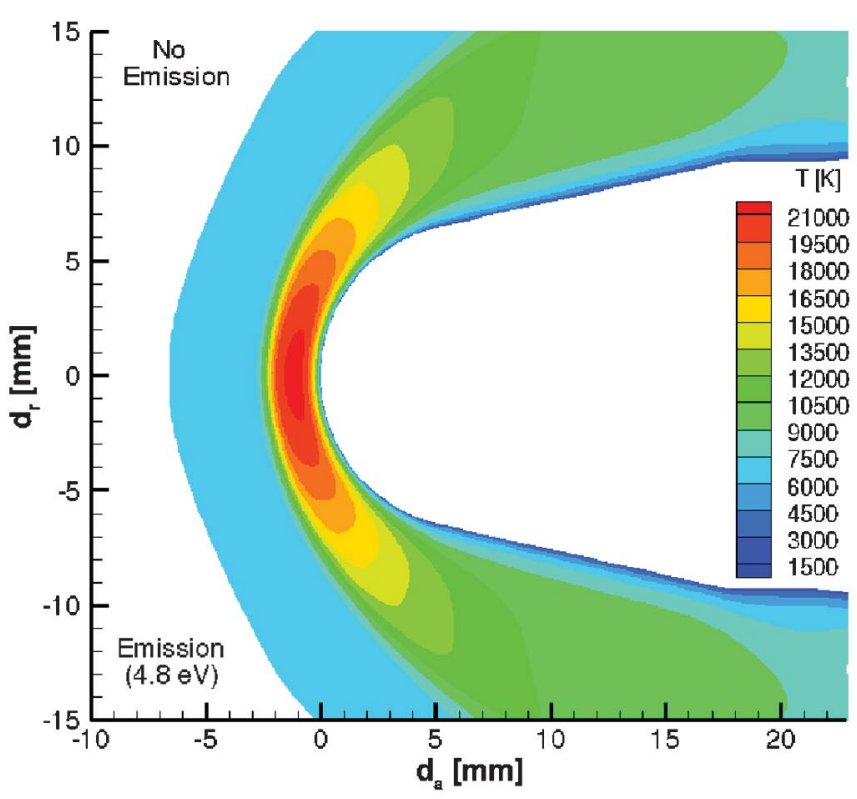

a) $\mathrm{S}-6(\epsilon=0.80)$

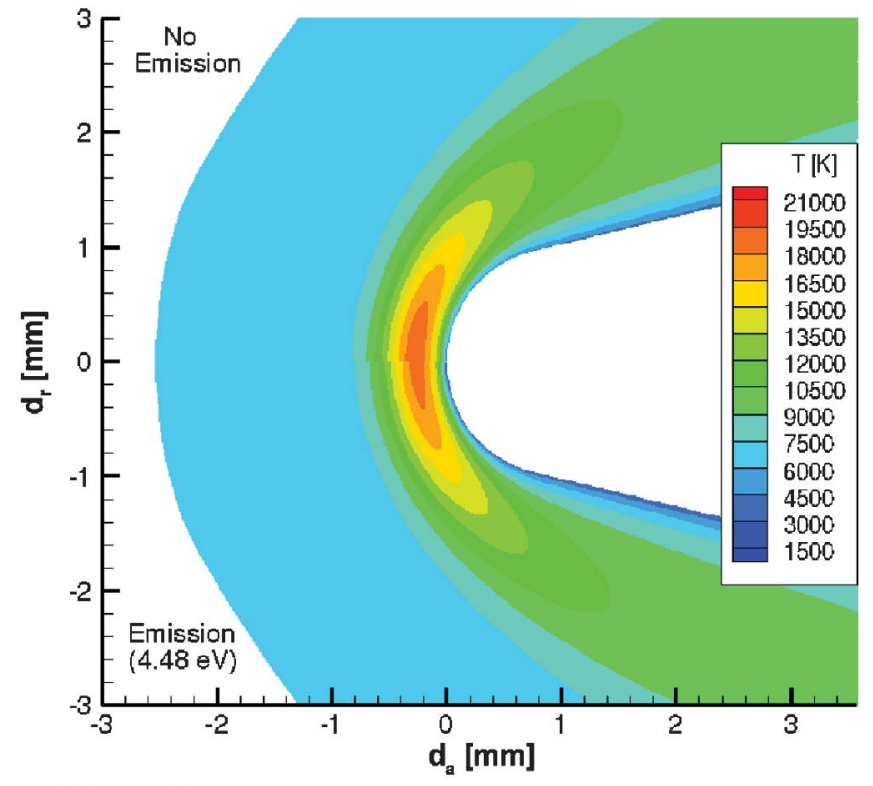

b) $\mathrm{S}-30(\epsilon=0.35)$

Fig. 5 Temperature contours for Mach 2.75 argon: without emission (top) and with emission (bottom).

The temperature and heat transfer distributions along the vehicle surface are presented in Figs. 9 and 10. Note that the distance along the leading edge is normalized by the leading-edge radius. Figure $\underline{9}$ shows the surface temperature and convective heat transfer for the Mach 2.75 air cases. For the S-6 geometry, emission with a work function corresponding to $4.8 \mathrm{eV}$ and emissivity of 0.80 results in a decrease in surface temperature and an increase in surface heat transfer. Although not shown, these trends also extend to the solutions obtained at the different air S-6 conditions (i.e., Mach number, emissivity, and work function). It is expected that a lower surface temperature corresponds to a higher convective heat transfer because the flowfield temperature is minimally changed by emission, and a larger temperature gradient will result in more convective heat transfer due to Fourier's Law. This trend is seen for the air S-30 geometry, where emission with a work function corresponding to $4.48 \mathrm{eV}$ and emissivity of 0.35 results in a decrease in surface temperature and an increase in convective heat transfer. This trend also extends to the other air S-30 conditions investigated. The Mach
2.75 argon cases' surface temperatures and convective heat transfers are shown in Fig. 10. For the S-30 geometry, emission with a work function of $4.48 \mathrm{eV}$ results in a lower surface temperature and higher convective heat transfer, which is the same trend as the air case for this geometry. For the S-6 geometry, emission with a work function of $4.8 \mathrm{eV}$ also results in a lower surface temperature and higher heat transfer, which is the same trend as the air case. Although not shown, the argon cases at various conditions (i.e., Mach number, emissivity, and work function) also result in lower surface temperature and higher heat transfer.

Figure 11 shows a comparison of radiative and emissive heat transfer for the Mach 2.75 cases with and without emission. For the cases without emission, radiative heat transfer equals the convective heat transfer (Figs. 9 and 10). For the cases with emission, the sum of emissive and radiative heat transfers equals the convective heat transfer. For the S-6 cases with emission, the radiative heat transfer is higher than the emissive heat transfer. For the S-30 cases with emission, the radiative heat transfer is lower than the emissive heat 


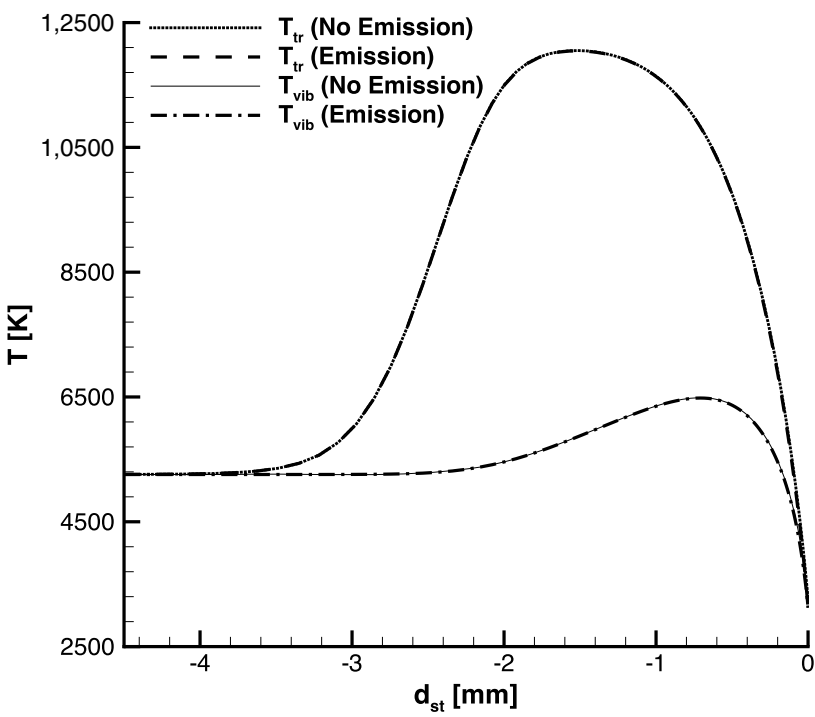

a) $\mathrm{S}-6(\epsilon=0.80, \Phi=4.8 \mathrm{eV}$ for emission $)$

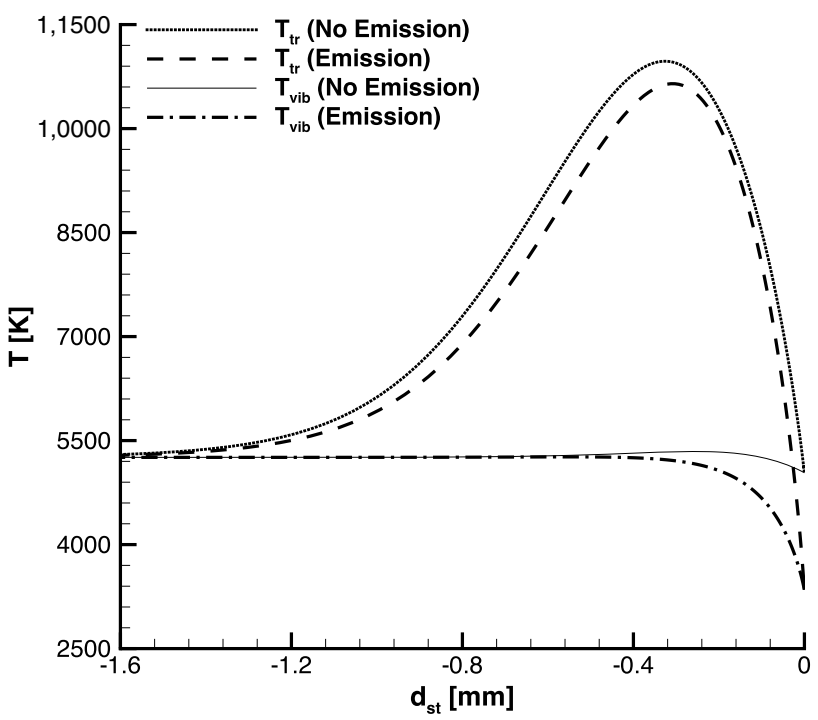

b) $\mathrm{S}-30$ ( $\epsilon=0.35, \Phi=4.48 \mathrm{eV}$ for emission)

Fig. 6 Temperature profiles along the stagnation line for the air Mach 2.75 cases.

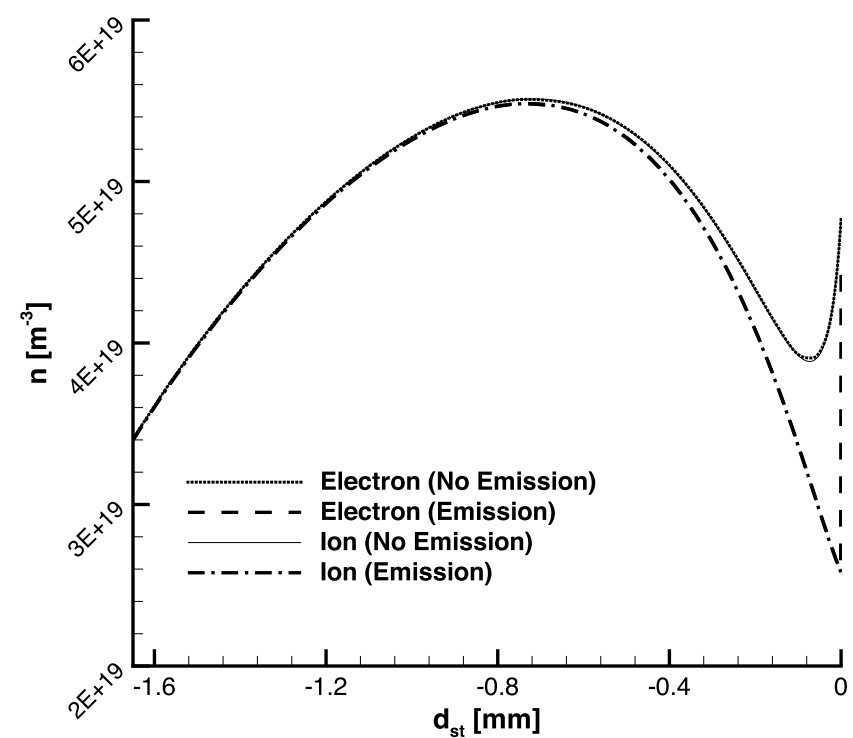

a) $\mathrm{S}-6(\epsilon=0.80, \Phi=4.8 \mathrm{eV}$ for emission $)$

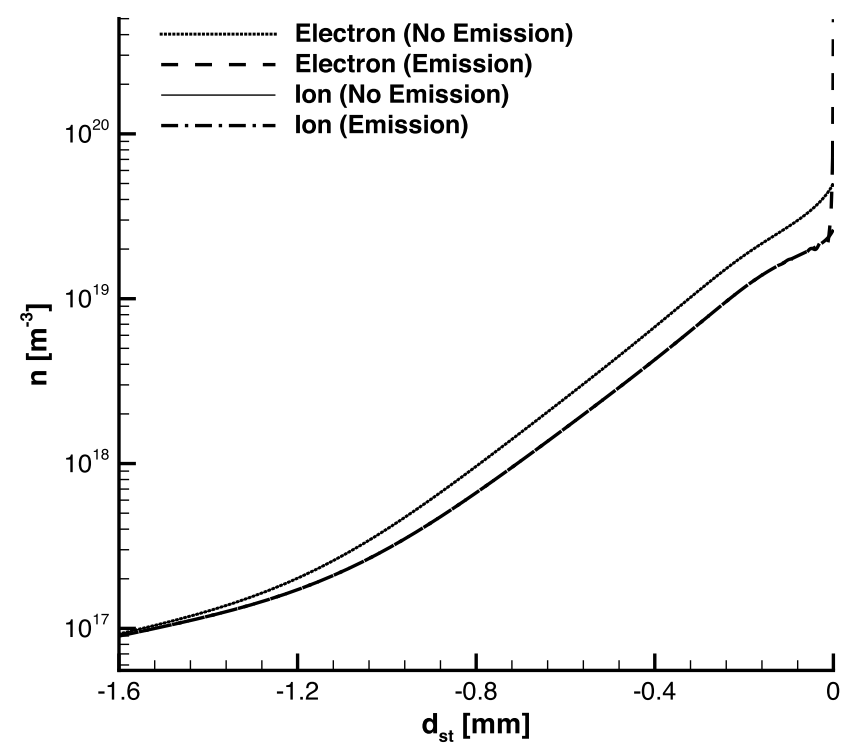

b) $\operatorname{S-30}(\epsilon=0.35, \Phi=4.48 \mathrm{eV}$ for emission $)$

Fig. 7 Number-density profiles along the stagnation line for the air Mach 2.75 cases.

transfer. This is expected because the S-6 geometry is graphite, which has a higher work function and emissivity than the S-30 geometry, which is tungsten. A high work function corresponds to emissive heat transfer being less effective, and a high emissivity corresponds to radiative heat transfer being more effective. The argon cases have higher surface temperatures than the air cases, which results in a higher level of emission, as shown in Fig. 12. The S-30 cases have significantly more emission, which is due the sharper leading edge, the lower work function of tungsten, and the lower emissivity of tungsten. The lower emissivity means that radiative heat transfer is less effective. This suggests that electron transpiration cooling is more effective for surfaces with lower emissivities.

The experiments measured the short-circuit currents from the emitter region, which are compared to the computational results in Tables $\underline{8}$ and $\underline{9}$ for the air cases. The experiments provided no uncertainties in the emitter current. For the S-6 emitter current, with graphite as the material, the computational results cover a range from $0.307 \mathrm{~A} / \mathrm{cm}^{2}$ for the Mach 2.5 case with a work function of $5.0 \mathrm{eV}$ and emissivity of 0.85 to $3.75 \mathrm{~A} / \mathrm{cm}^{2}$ for the Mach 3 case with a work function of $4.65 \mathrm{eV}$ and emissivity of 0.75 . The computational values agree reasonably well with the experimental value of $0.62 \mathrm{~A} / \mathrm{cm}^{2}$. For the S-30 emitter current, with tungsten as the material, the computational results cover a range from $1.56 \mathrm{~A} / \mathrm{cm}^{2}$ for the Mach 2.5 case with a work function of $4.65 \mathrm{eV}$ and emissivity of 0.4 to $10.9 \mathrm{~A} / \mathrm{cm}^{2}$ for the Mach 3 case with a work function of $4.32 \mathrm{eV}$ and emissivity of 0.3 . The computational values are higher than the measured value of $0.70 \mathrm{~A} / \mathrm{cm}^{2}$.

The measured short-circuit currents from the emitter region are compared to the argon computational results in Tables 10 and 11 . For the S-6 emitter current, with graphite as the material, the computational results cover a range from $0.900 \mathrm{~A} / \mathrm{cm}^{2}$ for the Mach 2.5 case with a work function of $5.0 \mathrm{eV}$ and emissivity of 0.85 to $4.36 \mathrm{~A} / \mathrm{cm}^{2}$ for the Mach 3 case with a work function of $4.65 \mathrm{eV}$ and emissivity of 0.75. The computational results agree well with the experimental value of $3.3 \mathrm{~A} / \mathrm{cm}^{6}$. For the $\mathrm{S}-30$ emitter current, with tungsten as the material, the computational results cover a range from $2.62 \mathrm{~A} / \mathrm{cm}^{2}$ for the Mach 2.5 case with a work function of $4.65 \mathrm{eV}$ and emissivity of 0.4 to $9.93 \mathrm{~A} / \mathrm{cm}^{2}$ for the Mach 3 case with a work function of 


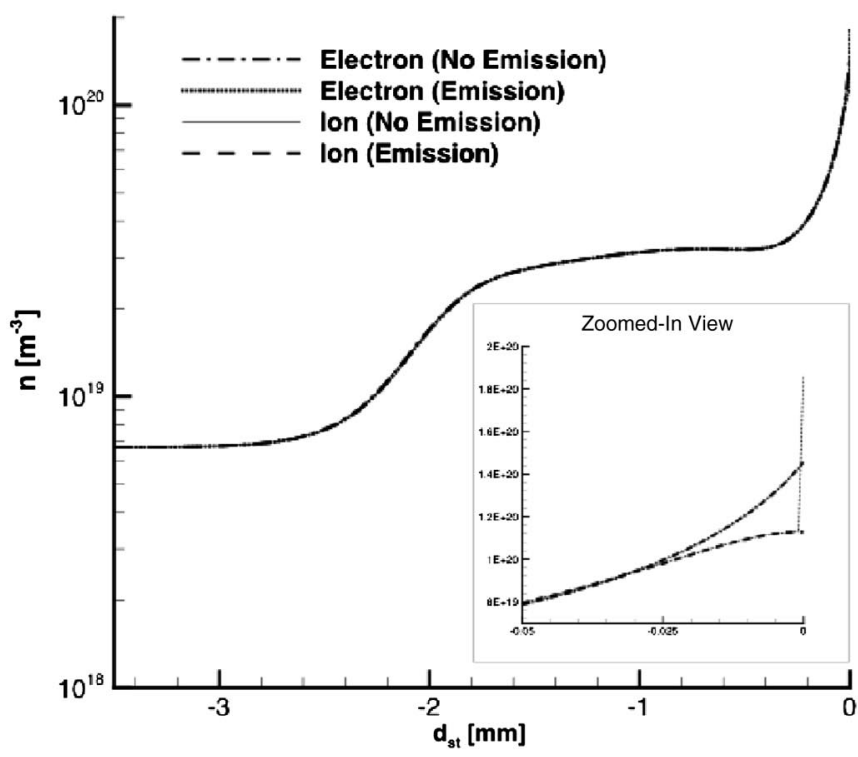

a) $\mathrm{S}-6(\epsilon=0.80, \Phi=4.8 \mathrm{eV}$ for emission $)$

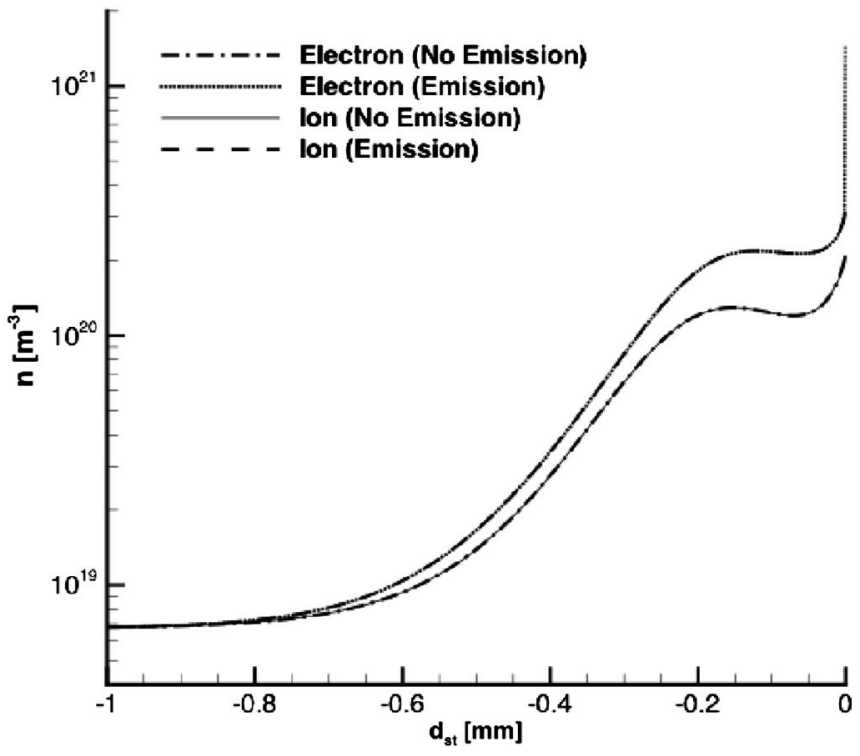

b) $\mathrm{S}-30(\epsilon=0.35, \Phi=4.48 \mathrm{eV}$ for emission)

Fig. 8 Number-density profiles along the stagnation line for the argon Mach 2.75 cases.

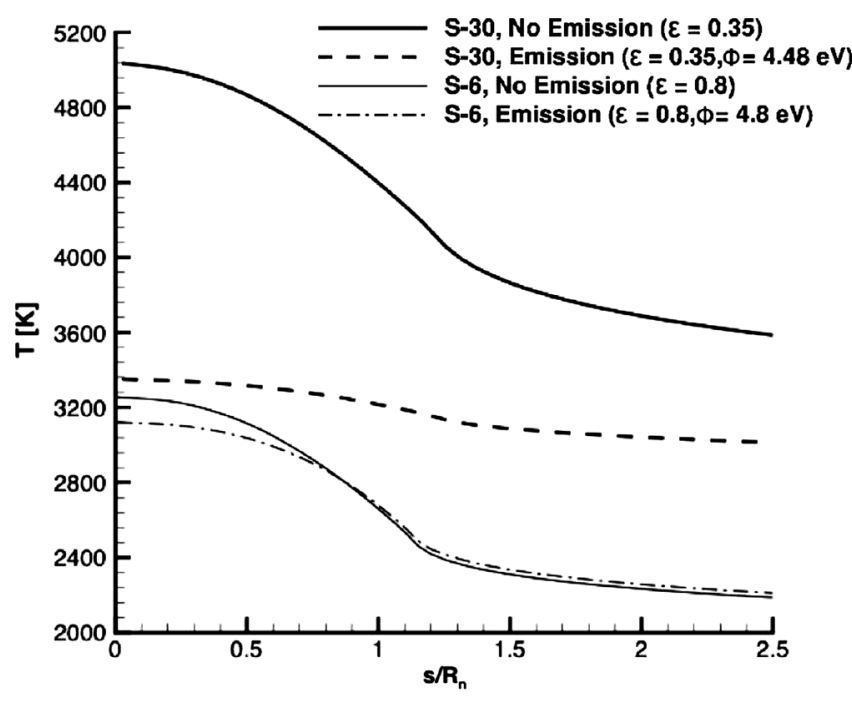

a) Surface temperature

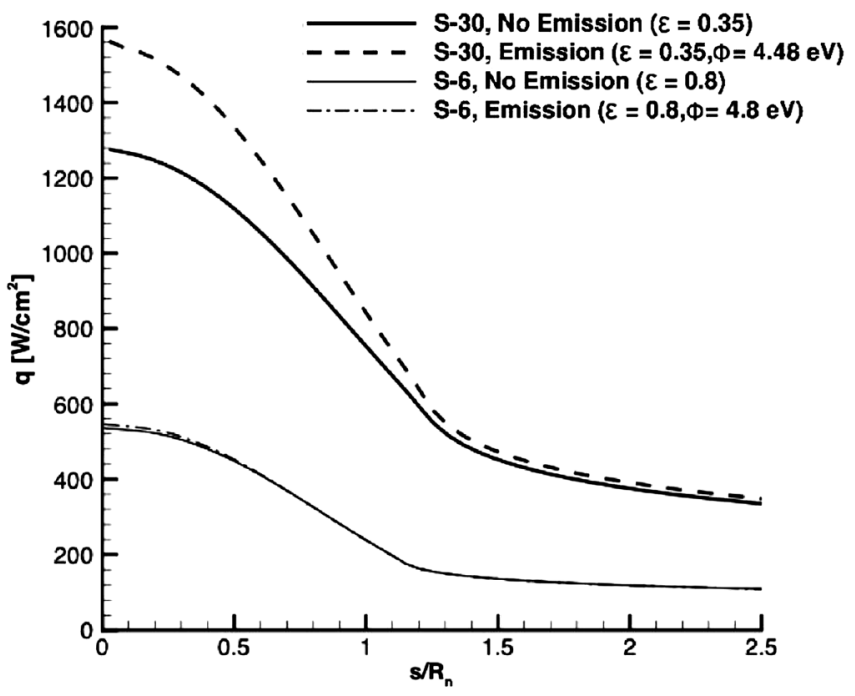

b) Heat transfer

Fig. 9 Surface temperature and heat transfer profiles for the air Mach 2.75 cases.
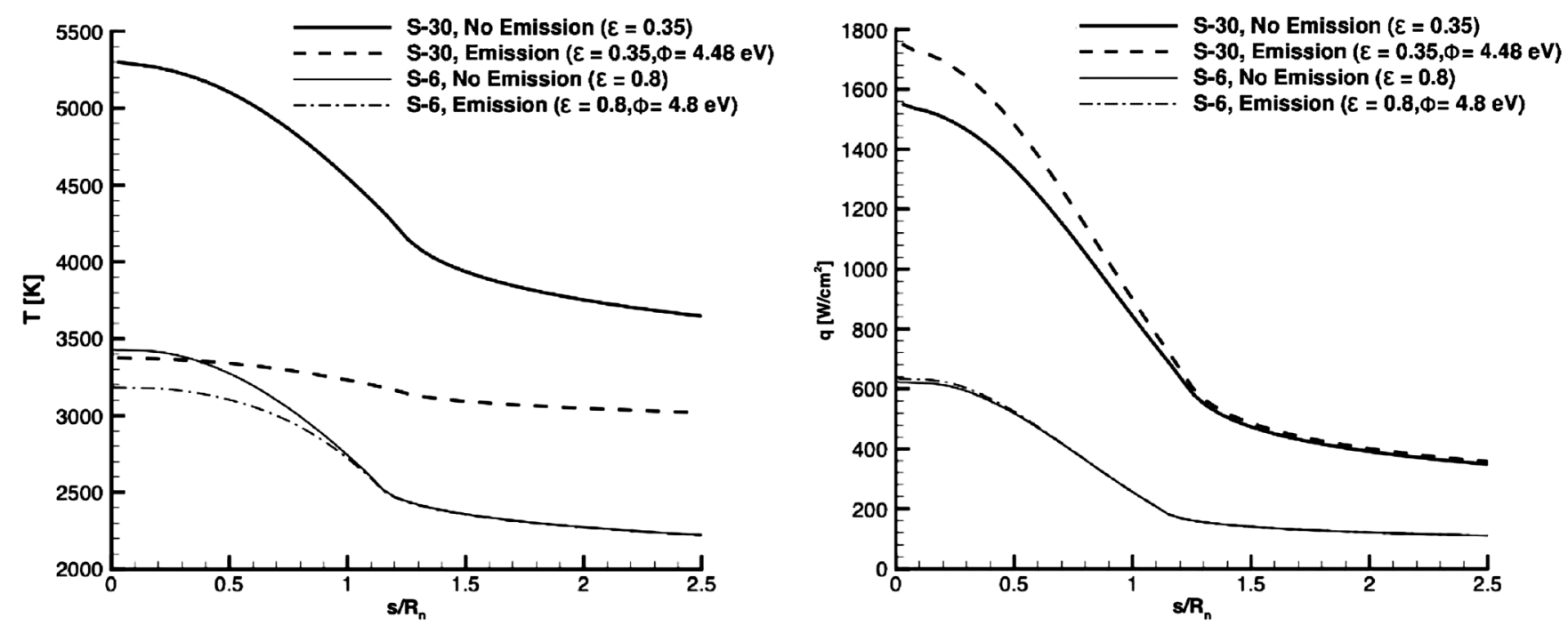

a) Surface temperature

b) Heat transfer

Fig. 10 Surface temperature and heat transfer profiles for the argon Mach 2.75 cases. 

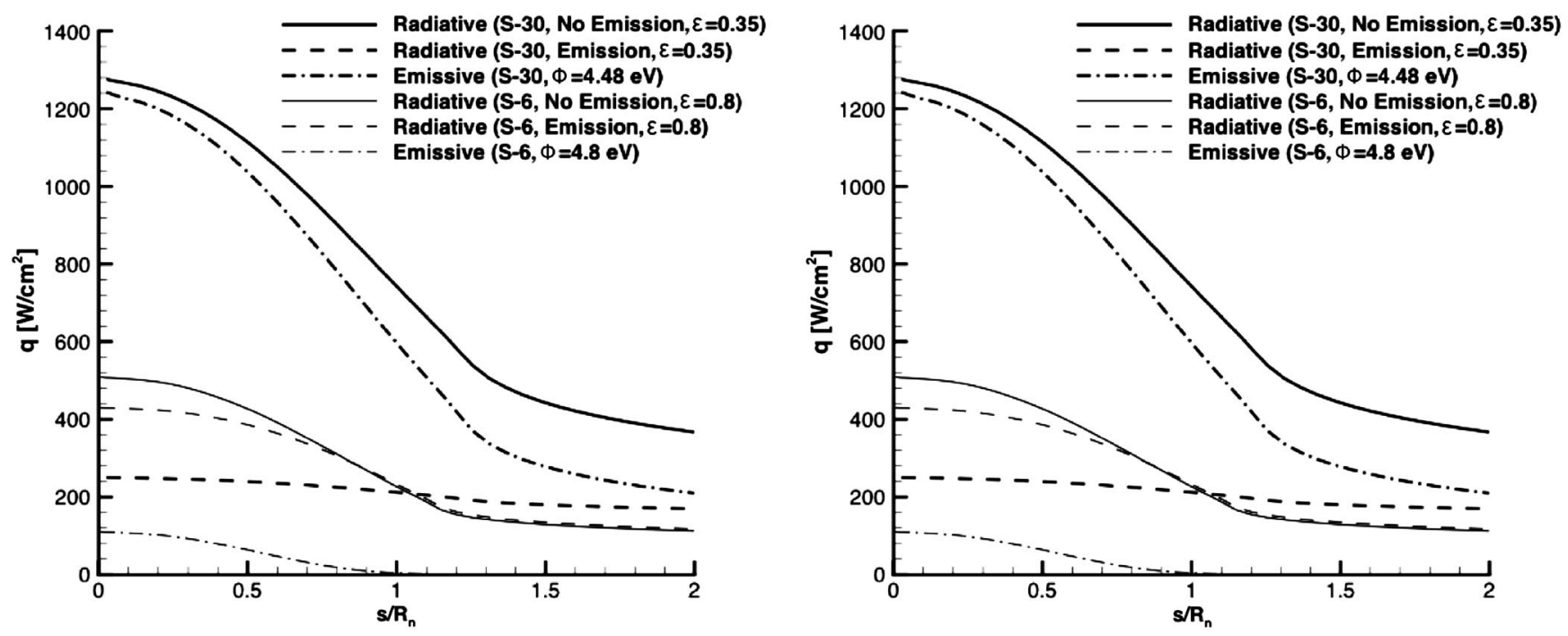

a) Air

b) Argon

Fig. 11 Radiative and emissive heat transfer profiles for the Mach 2.75 cases.

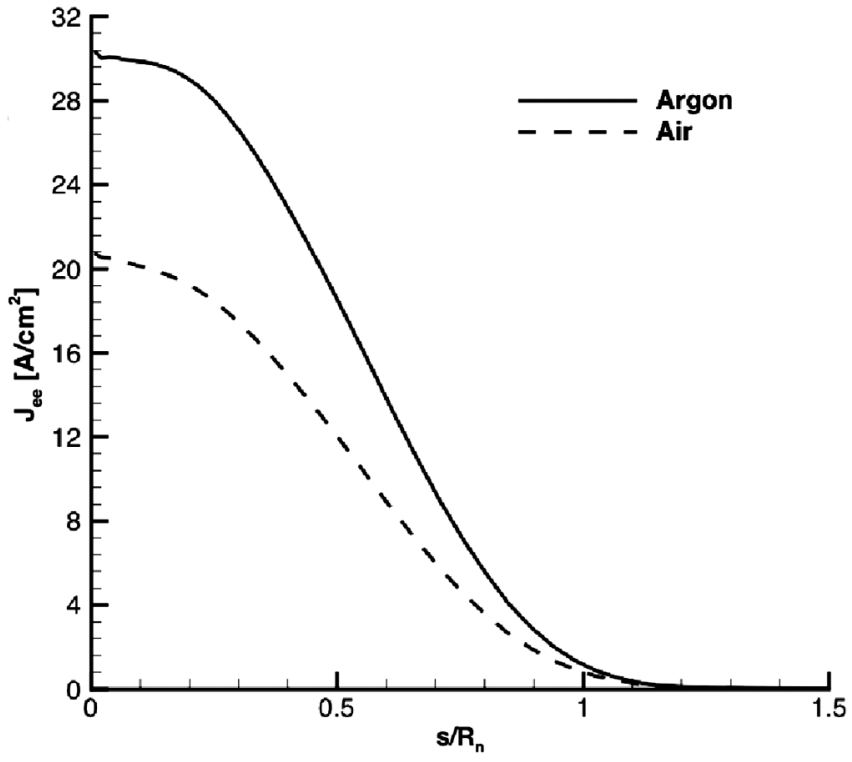

a) $\mathrm{S}-6(\Phi=4.8 \mathrm{eV}, \epsilon=0.80)$

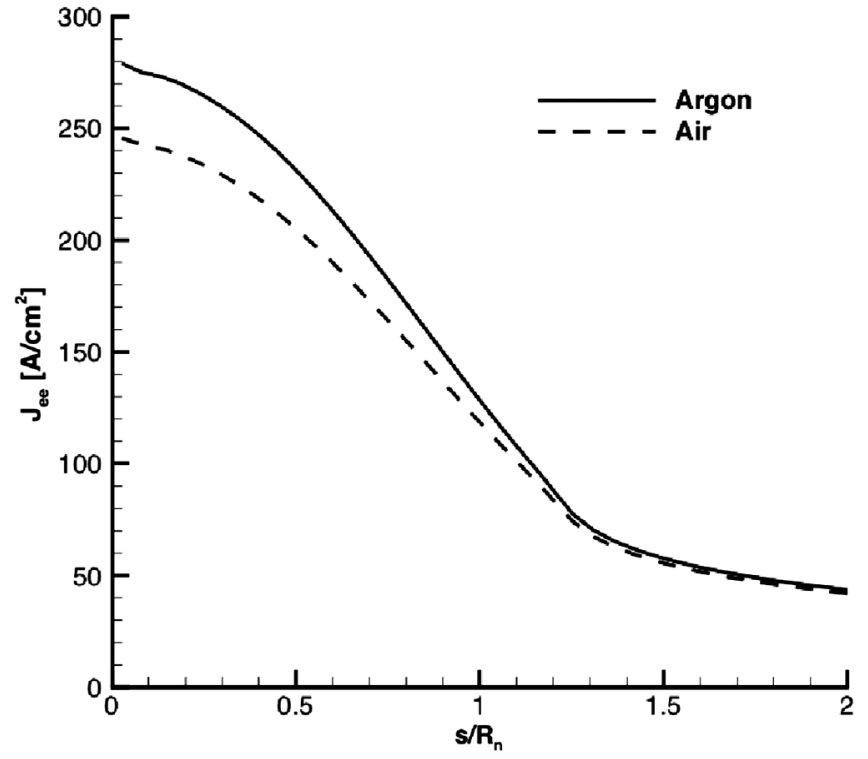

b) $\mathrm{S}-30(\Phi=4.48 \mathrm{eV}, \epsilon=\mathbf{0 . 3 5})$

Fig. 12 Surface profiles of emission current density for the Mach 2.75 cases.

Table 8 Experimental vs computational emitter current (in amperes per squared centimeter) for S-6 air cases

\begin{tabular}{|c|c|c|c|c|c|c|c|c|c|}
\hline \multirow[b]{2}{*}{ Mach number } & \multicolumn{3}{|c|}{$\epsilon=0.75$} & \multicolumn{3}{|c|}{$\epsilon=0.80$} & \multicolumn{3}{|c|}{$\epsilon=0.85$} \\
\hline & $\Phi=4.65 \mathrm{eV}$ & $\Phi=4.8 \mathrm{eV}$ & $\Phi=5.0 \mathrm{eV}$ & $\Phi=4.65 \mathrm{eV}$ & $\Phi=4.8 \mathrm{eV}$ & $\Phi=5.0 \mathrm{eV}$ & $\Phi=4.65 \mathrm{eV}$ & $\Phi=4.8 \mathrm{eV}$ & $\Phi=5.0 \mathrm{eV}$ \\
\hline 2.5 & 1.30 & 0.883 & 0.501 & 1.08 & 0.715 & 0.349 & 0.895 & 0.579 & 0.307 \\
\hline 2.75 & 2.48 & 1.79 & 1.12 & 2.12 & 1.51 & 0.913 & 1.82 & 1.27 & 0.745 \\
\hline 3.0 & 3.75 & 2.83 & 1.88 & 3.29 & 2.44 & 1.58 & 2.88 & 2.10 & 1.32 \\
\hline
\end{tabular}

${ }^{\mathrm{a}}$ Experimental $=0.62$ for all cases.

Table 9 Experimental vs computational emitter current (in amperes per squared centimeter) for S-30 air cases $^{\mathrm{a}}$

\begin{tabular}{|c|c|c|c|c|c|c|c|c|c|}
\hline \multirow[b]{2}{*}{ Mach number } & \multicolumn{3}{|c|}{$\epsilon=0.30$} & \multicolumn{3}{|c|}{$\epsilon=0.35$} & \multicolumn{3}{|c|}{$\epsilon=0.40$} \\
\hline & $\Phi=4.32 \mathrm{eV}$ & $\Phi=4.48 \mathrm{eV}$ & $\Phi=4.65 \mathrm{eV}$ & $\Phi=4.32 \mathrm{eV}$ & $\Phi=4.48 \mathrm{eV}$ & $\Phi=4.65 \mathrm{eV}$ & $\Phi=4.32 \mathrm{eV}$ & $\Phi=4.48 \mathrm{eV}$ & $\Phi=4.65 \mathrm{eV}$ \\
\hline 2.5 & 5.46 & 4.14 & 3.01 & 4.16 & 3.04 & 2.14 & 3.17 & 2.26 & 1.56 \\
\hline 2.75 & 8.22 & 6.47 & 4.89 & 6.53 & 4.95 & 3.61 & 5.16 & 3.79 & 2.69 \\
\hline
\end{tabular}

${ }^{\mathrm{a}}$ Experimental $=0.70$ for all cases. 
Table 10 Experimental vs computational emitter current (in amperes per squared centimeter) for S-6 argon cases ${ }^{\mathrm{a}}$

\begin{tabular}{|c|c|c|c|c|c|c|c|c|c|}
\hline \multirow[b]{2}{*}{ Mach number } & \multicolumn{3}{|c|}{$\epsilon=0.75$} & \multicolumn{3}{|c|}{$\epsilon=0.80$} & \multicolumn{3}{|c|}{$\epsilon=0.85$} \\
\hline & $\Phi=4.65 \mathrm{eV}$ & $\Phi=4.8 \mathrm{eV}$ & $\Phi=5.0 \mathrm{eV}$ & $\Phi=4.65 \mathrm{eV}$ & $\Phi=4.8 \mathrm{eV}$ & $\Phi=5.0 \mathrm{eV}$ & $\Phi=4.65 \mathrm{eV}$ & $\Phi=4.8 \mathrm{eV}$ & $\Phi=5.0 \mathrm{eV}$ \\
\hline 2.5 & 2.79 & 2.07 & 1.34 & 2.41 & 1.75 & 1.10 & 2.08 & 1.48 & 0.900 \\
\hline 2.75 & 3.59 & 2.68 & 1.83 & 3.14 & 2.31 & 1.53 & 2.74 & 1.98 & 1.28 \\
\hline 3.0 & 4.36 & 3.39 & 2.34 & 3.86 & 2.95 & 1.99 & 3.41 & 2.56 & 1.68 \\
\hline
\end{tabular}

${ }^{\mathrm{a}}$ Experimental $=3.3$ for all cases.

Table 11 Experimental vs. computational emitter current (in amperes per squared centimeter) for S-30 $\operatorname{argon}_{\text {cases }}{ }^{\mathrm{a}}$

\begin{tabular}{|c|c|c|c|c|c|c|c|c|c|}
\hline \multirow[b]{2}{*}{ Mach number } & \multicolumn{3}{|c|}{$\epsilon=0.30$} & \multicolumn{3}{|c|}{$\epsilon=0.35$} & \multicolumn{3}{|c|}{$\epsilon=0.40$} \\
\hline & $\Phi=4.32 \mathrm{eV}$ & $\Phi=4.48 \mathrm{eV}$ & $\Phi=4.65 \mathrm{eV}$ & $\Phi=4.32 \mathrm{eV}$ & $\Phi=4.48 \mathrm{eV}$ & $\Phi=4.65 \mathrm{eV}$ & $\Phi=4.32 \mathrm{eV}$ & $\Phi=4.48 \mathrm{eV}$ & $\Phi=4.65 \mathrm{eV}$ \\
\hline 2.5 & 8.07 & 6.37 & 4.84 & 6.37 & 4.84 & 3.54 & 5.01 & 3.69 & 2.62 \\
\hline 2.75 & 9.09 & 7.25 & 5.57 & 7.27 & 5.59 & 4.13 & 5.78 & 4.30 & 3.08 \\
\hline
\end{tabular}

${ }^{\mathrm{a}}$ Experimental $=3.3$ for all cases.

$4.32 \mathrm{eV}$ and emissivity of 0.3 . The experimental value of $3.3 \mathrm{~A} / \mathrm{cm}^{2}$ is within the range of computational results.

The computational results are generally higher than the experimental value for the air cases, especially for the S-30 tungsten cases. A potential explanation for why the computational cases for air are high is that the emissive surface could become oxidized under the experimental conditions, which would lead to an increase in the emissivity of surface [33]. This increase in surface emissivity would make radiation more effective at cooling the surface, which would lower the emitted current. The computational results are an overestimation because the current numerical method does not model recombination of electrons (i.e., plasma sheath physics) other than through recombination with flowfield ions at the assumed fully catalytic wall, which would reduce the emitted current. The numerical method also assumes the work function of the material is constant, whereas it may change as the material degrades under hightemperature exposure. Given the uncertainties in the freestream conditions (Mach number) and emissive surface properties (material work function and emissivity) of the experiments, the level of agreement obtained is considered satisfactory. The comparisons also provide motivation for new experiments to be performed and for further refinement of the computational models to better understand the potential benefits of electron transpiration cooling.

\section{Conclusions}

The goal of the present work was to assess current electron transpiration cooling modeling approaches using a set of experiments performed in the 1960s for a range of freestream conditions, emissive materials, and geometries. The experiments measured the electron current from the emitter region of the geometry and comparisons were made to the modeling approach for air and argon fluids, graphite and tungsten emissive materials, and two different geometries. The computational results produced a wide range of emitted current due to the uncertainty in the freestream conditions and emissive material, but they still agreed well with the experiments. The results also showed that emission was a more effective cooling mechanism for surfaces with sharper leading edges, lower work functions, and lower emissivities.

\section{Acknowledgments}

The authors gratefully acknowledge support for this work from the Lockheed Martin Corporation. In addition, we thank Luke Uribarri and Edward Allen of Lockheed for essential technical oversight. The authors also thank Erin Farbar and Kentaro Hara from the University of Michigan for several useful discussions. This research was supported in part through computational resources and services provided by Advanced Research Computing at the University of Michigan in Ann Arbor.

\section{References}

[1] Fay, J. A., and Riddell, F. R., "Theory of Stagnation Point Heat Transfer in Dissociated Air," Journal of the Aeronautics Sciences, Vol. 25, No. 2, 1958, pp. 73-85.

[2] Voland, R. T., Huebner, L. D., and McClinton, C. R., "X-43A Hypersonic Vehicle Technology Development," Acta Astronautica, Vol. 57, Nos. 2-8, 2005, pp. 614-622.

doi:10.1016/j.actaastro.2005.03.061

[3] Glass, D. E., "Physical Challenges and Limitations Confronting the Use of UHTCs on Hypersonic Vehicles," 17th AIAA International Space Planes and Hypersonic Systems and Technologies Conference, AIAA Paper 2011-2304, April 2011.

[4] Uribarri, L. A., and Allen, E. H., "Electron Transpiration Cooling for Hot Aerospace Surfaces," 20th AIAA International Space Planes and Hypersonic Systems and Technologies Conference, AIAA Paper 20153674, July 2015.

[5] Alkandry, H., Hanquist, K. M., and Boyd, I. D.,"“'Conceptual Analysis of Electron Transpiration Cooling for the Leading Edges of Hypersonic Vehicles," 11th AIAA/ASME Joint Thermophysics and Heat Transfer Conference, AIAA Paper 2014-2674, June 2014.

[6] Touryan, K. J., "A Hypersonic Plasma Power Generator," AIAA Journal, Vol. 3, No. 4, 1965, pp. 652-659. doi: $10.2514 / 3.2942$

[7] LeBlanc, A. R., and Grannemann, W. W., "Thermionic Generator for Re-Entry Vehicles," Proceedings of the IEEE, Vol. 52, No. 11, 1964, pp. $1302-1310$. doi:10.1109/PROC.1964.3366

[8] Touryan, K. J., "The Hypersonic Plasma Converter: II," Sandia Lab. Rept. SC-RR-4960, Albuquerque, NM, 1964.

[9] Martin, A., Scalabrin, L. C., and Boyd, I. D., "High Performance Modeling of Atmospheric Re-Entry Vehicles," Journal of Physics: Conference Series, Vol. 341, No. 1, 2012, Paper 012002.

[10] Wilke, C. R., "A Viscosity Equation for Gas Mixtures," Journal of Chemical Physics, Vol. 18, No. 4, 1950, pp. 517-519. doi:10.1063/1.1747673

[11] Vincenti, W. G., and Kruger, C. H., Introduction to Physical Gas Dynamics, Krieger, New York, 2002, pp. 12-14,18-26, 162-165.

[12] Blottner, F. G., Johnson, M., and Ellis, M., "Chemically Reacting Viscous Flow Program for Multi-Component Gas Mixtures," Sandia Lab. Rept. SC-RR-70-754, Albuquerque, NM, 1971.

[13] MacCormack, R. W., and Candler, G. V., "The Solution of the NavierStokes Equations Using Gauss-Seidel Line Relaxation," Computers and Fluids, Vol. 17, No. 1, 1989, pp. 135-150. doi:10.1016/0045-7930(89)90012-1

[14] Karypis, G., and Kumar, V., METIS: A Software Package for Partitioning Unstructured Graphs, Partitioning Meshes, and Computing Fill-Reducing Ordering of Sparse Matrices, Univ. of Minnesota, Minneapolis, MN, 1998, pp. 1-44.

[15] Park, C., Nonequilibrium Hypersonic Aerothermodynamics, Wiley, New York, 1990, pp. 145-170. 
[16] Park, C., and Lee, S. H., "Validation of Multi-Temperature Nozzle Flow Code NOZNT," Journal of Thermophysics and Heat Transfer, Vol. 9, No. 1, 1995, pp. 9-16 doi: $10.2514 / 3.622$

[17] George, C., Candler, G., and Pfender, E., "An Implicit Algorithm to Simulate Reaction Chemistry in a Plasma," Journal of Physics D: Applied Physics, Vol. 31, No. 18, 1998, pp. 2269-2280. doi:10.1088/0022-3727/31/18/012

[18] Richardson, O. W., The Emission of Electricity from Hot Bodies, Longmans, Green, and Co., London, 1921, pp. 60-116, 154-195.

[19] Haynes, W. M., CRC Handbook of Chemistry and Physics, 94th ed., CRC Press, Boca Raton, FL, 2013, pp. 12-124 (Sec. 12, p. 124).

[20] Scott, C. D., "Wall Catalytic Recombination and Boundary Conditions in Nonequilibrium Hypersonic Flows-With Applications," Advances in Hypersonics - Modeling Hypersonic Flows, Vol. 2, Birkhäuser, Boston, 1992, pp. 176-250.

[21] Lieberman, M. A., and Lichtenberg, A. J., Principles of Plasma Discharges and Materials Processing, Wiley, New York, 1994, pp. 25 30.

[22] Razier, Y. P., Gas Discharge Physics, Springer-Verlag, Berlin, 1991, pp. 281-282.

[23] Benilov, M. S., and Marotta, A., "A Model of the Cathode Region of Atmospheric Pressure Arcs," Journal of Physics D: Applied Physics, Vol. 28, No. 9, 1995, pp. 1869-1882. doi: $10.1088 / 0022-3727 / 28 / 9 / 015$

[24] Fridman, A., and Kennedy, L. A., Plasma Physics and Engineering, Taylor and Francis, New York, 2004, pp. 505-508.
[25] Krishnan, K. S., and Jain, S. C., "Thermionic Constants of Graphite," Nature, Vol. 169, No. 4304, 1952, pp. 702-703. doi:10.1038/169702c0

[26] Reiman, A. L., "Thermionic Emission from Carbon," Proceedings of the Physical Society, Vol. 50, No. 4, 1938, pp. 496-500. doi:10.1088/0959-5309/50/4/302

[27] Nichols, M. H., "The Thermionic Constants of Tungsten as a Functions of Crystallographic Direction," Physical Review Letters, Vol. 57, No. 4, 1940, pp. 297-306.

[28] Touloukian, Y. S., Thermophysical Properties of Matter, the TPRC Data Series: A Comprehensive Compilation of Data, Vols. 7-8, IFI-Plenum, New York, 1970, pp. 783-788, 31-37.

[29] McBride, B. J., and Gordon, S., "Computer Program for Calculation of Complex Chemical Equilibrium Compositions and Applications," NASA Reference Publ. 1311, June 1996.

[30] Lofthouse, A. J., Scalabrin, L. C., and Boyd, I. D., "Velocity Slip and Temperature Jump in Hypersonic Aerothermodynamics," Journal of Thermophysics and Heat Transfer, Vol. 22, No. 1, 2008, pp. 38-49. doi: $10.2514 / 1.31280$

[31] Moore, C. E., "Atomic Energy Levels as Derived from the Analysis of Optical Spectra, Volume 1," Circular of the Bureau of Standards, Vol. 1, No. 467, 1949, pp. 211-215.

[32] Boulos, M. I., Fauchais, P., and Pfender, E., "Thermodynamic Properties," Thermal Plasmas: Fundamentals and Applications, Vol. 1, Springer Science and Business Media, New York, 1994, pp. 213-264.

[33] Howell, J. R., Siegal, R., and Menguc, M. P., Thermal Radiation Heat Transfer, CRC Press, London, 2011, pp. 129-135. 